\title{
BIM and cultural heritage: compatibility tests in an archaeological site
}

\author{
C. Achille, N. Lombardini \& C. Tommasi \\ $3 D$ Survey Group, ABC Department, Politecnico di Milano, Italy
}

\begin{abstract}
Nowadays, when people speak about BIM software, they refer to new constructions, made by regular elements and standard parameters. The question is: what happens when you, instead of a new building, consider an ancient or existing one? To answer this question, we have evaluated the possibility of using the BIM process effectively for the conservation and proclamation of Cultural Heritage. The target is to test the BIM programs, satisfying the requirements of new buildings, and see if they can also be successfully used in complex situations, like the ones linked to the Cultural Heritage field, where you have to consider the unicity of the architectural elements, the constructive systems and materials (those are not standardized as the new ones), the degradation of the structures and the environmental conditions. In particular, the research examines the case study of the archaeological area of the Sanctuary of Diana in Nemi (Rome), which is an important example in the National Heritage. The final product consists of a parametric model, where you can find, embedded in a database, all the information about the elements and the management of conservation projects. Highlighting positive aspects and existing limits we want to contribute to further studies on the subject, leading to a mandatory implementation and use of this software, even in relation to future European legislative framework.
\end{abstract}

Keywords: BIM, cultural heritage, survey, conservation, maintenance.

\section{Introduction}

The paper specifically focuses on the theme of Archaeological Heritage that is defined by ICOMOS: "The archaeological heritage is that part of the material heritage in respect of which archaeological methods provide primary information. It comprises all vestiges of human existence and consists of places relating to all 
manifestations of human activity, abandoned structures, and remains of all kinds (including subterranean and underwater sites), together with all the portable cultural material associated with them " ICOMOS [1].

The choice to deal with the study of an archaeological site is determined by the urgency to protect and conserve them (e.g. the Italian case of Pompeii). As "the overall objective of archaeological heritage management should be the preservation of monuments and sites in situ, including proper long-term conservation and curation of all related records and collections etc." ICOMOS [1], it's necessary to verify the possibility of a parametric model, interoperable, semantic and clever, capable of offering a 3D representation of the heritage within all the information about its life cycle and all the survey made during time. Also the complexity proper of archaeological heritage of some characteristics (historical, architectonical, structural, constructive, materials and decay) makes the case study interesting in order to evaluate the feasibility of several operative and management procedures [2].

The aim of the research in progress today is to test, with real data and real case studies from $\mathrm{CH}$ word, the BIM process and highlight the difficulties in order to improve it. Nowadays, we are looking at a constant diffusion of BIM systems among different fields of application. BIM is not a single software, but it is a process that support the information sharing and the maintenance of buildings. HARPACEAS [3] teaches in fact that the BIM modules are three: "Authoring", that include all the software that build the 3D model; "Tools", that is used for the computes and the information about the materials in the construction site; "Review", that has to check the final model completed with all the information, and be sure that the structural, architectural and plant models correspond.

It is clear that the potential that until now has been used mostly in the new constructions field, can be adapted and refined in the Cultural Heritage word.

Before showing the case study, it is important to know which data that are managed in $\mathrm{CH}$ field, especially in archaeological areas.

\section{What the $\mathrm{CH}$ need from a BIM system?}

What is interesting for the potentiality offered by the BIM technology is the methodical approach not only for the interventions needed, but also for the management of the cultural heritage, with the activities to monitor its health condition and the maintenance. The working method realized using these instruments would allow the achievement of these tasks:

- The digital representation of the existing building;

- An informative database about all the different elements of the heritage;

- A recurring checking of the health condition of the heritage;

- The evaluation of the effects of different typology of intervention.

The management of existing site has different needs from the new buildings, and it is important to know the precise information that the model must contain:

- Geo localization 
- Shape of the element

- Materials

- Different layers of materials

- State of decay

- Historical information

- Environmental conditions

\subsection{State of art}

Many researches are focusing their attention on building a system that can be adapted to all $\mathrm{CH}$ cases studies, even to the archaeological areas [4]; however, it is still very difficult to find it because each situation is very different from the others, having particular and unique needs and history. For this reason, hard structured information system cannot be actually used in $\mathrm{CH}$ field, which requires more dynamic systems, capable of self-adapting to every case for covering all possible needs. Nowadays, we can distinguish two different categories of software related to $3 \mathrm{D}$ models; for now, the BIM software are not able to solve all the issues that come from the modelling of the $\mathrm{CH}$, but they need the integration with other instrument to reach a sufficient result: 3D modelling software and BIM software. The first category include the modelling software (as for example 3DStudio, AutoCad, Rhinoceros etc.) that can manage real based 3D models. These models can be characterized by high complexity, great accuracy, high-resolution and heterogeneous features (both line based and surface based at the same time), represented through Mesh and Nurbs. Normally these models are directly created from 3D dense point clouds, coming from survey.

On the other hand, when we speak about BIM software, it is important to know that the most important letter of the word BIM is the "I"- Information - as they add to the 3D buildings models an information system, namely connecting digital models with different kind of information useful for building management.

Revit, for example, is one of best known "building design software specifically built for Building Information Modelling (BIM), with features for architectural design, (MEP and structural engineering, and construction)" based on "parametric components" [5]. BIM software offer hard structured information system able to connect data and information to the objects, with the possibility to perform queries and simulations on them. Inside the universe BIM, there is an experimental process called HBIM, explained by Dore and Murphy [6], that represent an example of BIM specifically directed to Digital Heritage. It is a novel prototype library of parametric objects based on historic architectural data and a system of cross platform programs for mapping parametric objects onto a point clod and image survey data $[7,8]$. From all the case studies considered emerged the fundamental features that all the BIM software should have to operate in $\mathrm{CH}$ :

- To be able to collect historical-cultural information to understand where to operate;

- To guarantee the possibility of managing the survey data (CAD, point clouds), to ease the operation of virtual reconstruction of the building; 
- $\quad$ To foresee the possibility of modifying or implementing, any time and by any operator, to ensure both the update of all the information linked to the different elements and the validity of the evaluations on the present state of the heritage;

- To let the construction of an informative and open database, containing the indications about the materials and the constructive methodologies of the building;

- To ensure the exchange of different data between different parametric or nonparametric software, thanks to the identification of some format (IFC, XLM, etc.).

To make the BIM systems become convenient in $\mathrm{CH}$, instead of using normal 3D modelling software, some operative issues have to be resolved:

- lack of interoperability between BIM and the technologies for topographical survey; hard management of heavy data coming from surveying instrument (e.g. laser scanner, photogrammetry, etc.) such as huge point clouds;

- $\quad$ simplification of the geometry of the monument;

- complexity in the restitution of the unicity and of the details of the historical elements;

- inability to assign punctually specific data to points placed in the surface of the object.

The need to ease the process of 3D model production and graphical elaborations for the $\mathrm{CH}$ became a goal not only for a correct reproduction of the existing monument, but also for a complete comprehension of the hierarchical logic between the parts of the monument.

\subsection{BIM system data interaction}

\subsubsection{Survey data}

There are three common methods to survey a monument, an historical building or an archaeological area: the direct survey, the photogrammetric survey and the topographical survey. Even if the restitution of a historical building is a coordination of these three methods, the focus is on the data that comes from the photogrammetric and topographical survey. These two methods generate one product - the point cloud - through different means. The management of point clouds is one of the bigger problems of BIM applied to $\mathrm{CH}$. This is an issue faced last year by several design platform (e.g. Autocad 2015 added the function "attach point cloud") and the BIM system is trying to catch up: now the software is able to import point clouds, but it's important to underline that is not easy to manage them. These are the most common problems that we incurred opening the point clouds in Graphisoft Archicad and Autodesk Revit:

- Impossibility to import big point clouds (with millions point), making it impossible to reach an high level of details;

- Impossibility to recognize the points as snap point and redraw the profiles;

- Impossibility to edit the surfaces created with the triangulation. 
Some plug-ins are available in order to solve in part the problems, for example Green Spider for Revit developed by Garagnani and Manferdini [9] and Cadimage for Archicad, that improve the functionalities of the original programs as the recognizing of the points as snap. Given that BIM is not a single software, but a process, it is impossible to have one unique program that solve all the matters. For that reason, some software mediate between the instrument for surveying (e.g. laser scanner) and the BIM modeller (e.g. Archicad, Revit, Allplan, etc.), e.g. one program created with this aim is Scalypso [10].

\subsubsection{Materials browser}

The parametrization process includes the materials used in building the existent structures. The aleatory knowledge of the materials is fundamentally due to a lack in their standardization.

The knowledge of the behaviour of existing buildings (not necessarily ancient or "monumental") is based on the specific study of the material features, acquired with methodical and destructive instrumentations (destructive tests) and/or nondestructive ones (NDT).

There are many limitations in the knowledge of ancient materials and building techniques but, above all, there is a very poor knowledge about the real compliance of what was built with what is written in the treatises, the manuals, the rules and the project elaborations.

Anyway, despite all the inquiries, one cannot reach a complete knowledge of the ancient materials (the data or the parameters are of structural, physical and termo-physical kind); moreover, in general terms, in the databases of the examined softwares only data relevant to modern materials can be found.

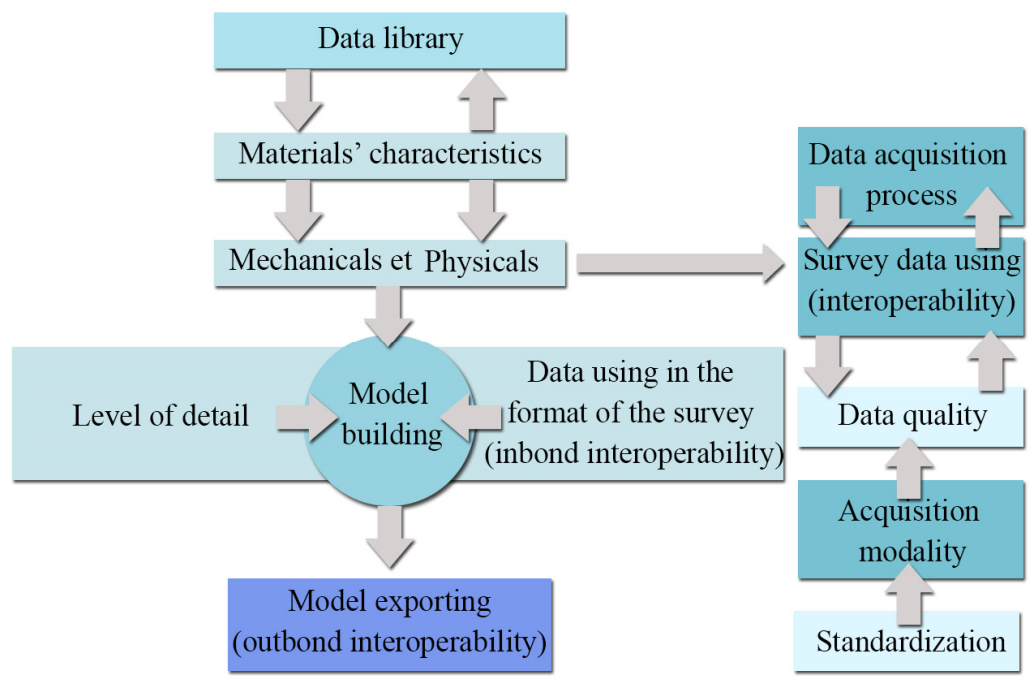

Figure 1: Workflow of the management of the data related to the construction materials in order of their implementation and their use by the BIM software. 
This objective limitation on the knowledge of the material parameters implies that, in the actual state of the art, one has to define, case by case, knowledge level standards in a way that he can have a control on the approximation level reached in each single case. We have to aspire to a standardization in the definition and in the use of these data (a sort of a standard knowledge level, as defined in the structural field by the Italian Technical Rules for the existing structures) [11].

\section{Case study: BIM applied to the archaeological area of Nemi (Rome)}

\subsection{General overview}

Nemi is a small city, located in the middle of "Colli Albani" in Rome surroundings. The place is well known for the roman ships, recovered in the 1930s and destroyed during the Second World War. Several interesting places of archaeological interest are distributed along and near the lake. One of the most famous is the Sanctuary of Diana. Up to now the temple has been excavated, several parts of the Sanctuary and the so called "celle donarie". Starting from the data that we surveyed there, we tried to elaborate them in a BIM process. The aim is to study a new system for covering the site and to obtain a smart model, plenty of information. The collected and available data in this case study are: the laser scanner and photogrammetrical survey of the ruins; the survey of the materials of the Sanctuary and of the Cells; the state of decay of the roman masonry structures of the Sanctuary and of the Cells; the micro environmental conditions of temperature, (humidity, rising dump in the masonries and ventilation) and the critical collection of historical documents, especially in order to deeply evaluate the constructive methods adopted I this ancient structures built in opus incertum, opus reticulatum, and mixtum (we are speaking about masonries composed by a core of roman concrete protected by faces of pyramid blocks made in "peperino" - a volcanic tuff excavated in quarries very close to Nemi).
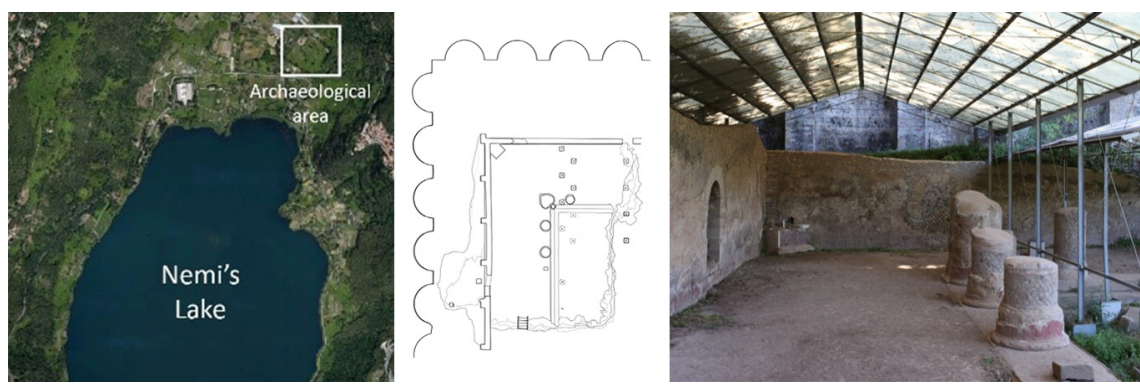

Figure 2: Localization of the area in the lake (on the left), Diana's Sanctuary planimetry (in the middle) and photo of the Sanctuary (on the right).

In the same time was surveyed the existing coverage that is interesting one side of the Sanctuary, so called "Portico". Once all the information were collected, the 
next phase was to put them in one container: in the market, there are several BIM software certified by Building Smart [12], an organization that promotes the interoperability (open information exchange) between the different BIM instruments. To run the compatibility tests we chose the two most used one: Graphisoft Archicad and Autodesk Revit.

The available information about Nemi coming from the survey can be divided in three categories: text, raster and vectorial. For each category, we made several attempt with different instruments that the two software gave us, in order to define the best solutions for information exchanging and time saving.

\subsection{Data management: text and raster}

When we speak about text, we refer to the specific information about the materials, the decay, micro environmental, etc. What is required from a BIM software is the freedom to assign specific characteristics to specific points, but these software generally work for elements and components and they do not recognize the single points on their surface.

This is a problem for the $\mathrm{CH}$ field, where potentially every point of the surface can have different parameters, considering also not only the specific characteristics that are not standardized, but also their damages. We partially resolve it putting some tags in selected points.

Regarding the metrical images (e.g. the ortophotos), they was useful to do the 3D reconstruction of the shapes and to read the walls, and also to create materials for the material library (e.g. different type of stone, Figure 3).
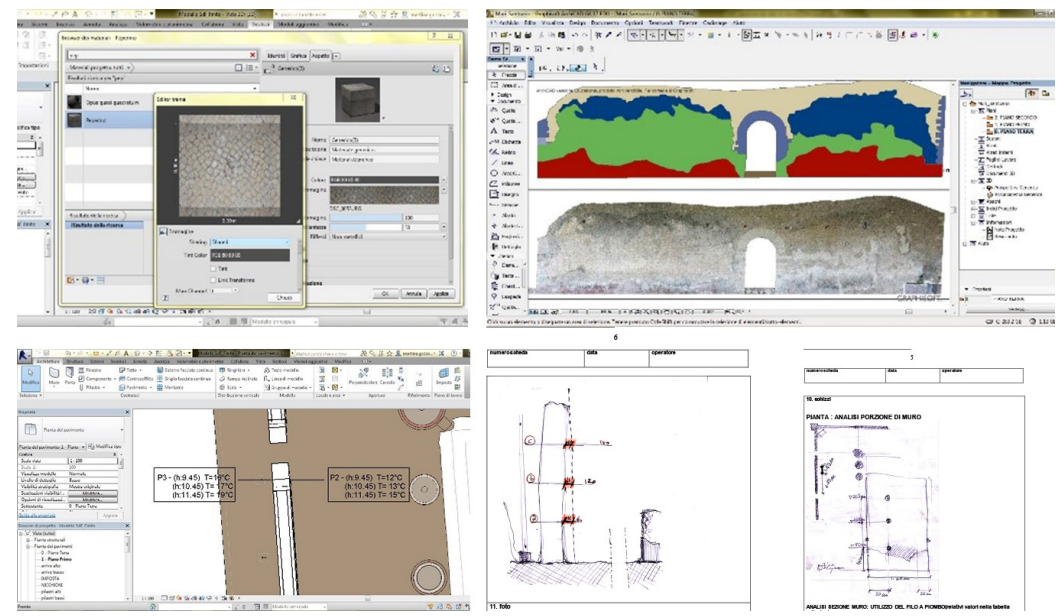

Figure 3: Top line: Material's browser: how it look like (on the left). Nemi case study: peperino material, image inserted during the research phase. Insertion of raster data and modelling of the walls (on the right). Bottom line: Environmental data management: placement of tags with temperature data (on the left), coming from hand drawings made in site (on the right). 


\subsection{Data management: CAD and point clouds}

The CAD file can be a product of direct survey, so it is important to be able to handle it easily with the BIM software. In general, we can say that while in Archicad there are no issues in managing them, instead in Revit the format can be imported and correctly viewed but the files cannot be edited, and they will only work as tracing path. On the other hand, when we speak about point clouds, we refer to the product of laser scanner survey or photogrammetric survey. The management of this type of data is more complex, and, as said before, it is one of the biggest problem of BIM technology in $\mathrm{CH}$ field. The two software manage these types of data in different way: with Revit it's possible to create some slides of the point cloud, and it is able to manage complete and big cloud, it is not necessary to reduce it before the import in the software. However, the tests highlight the limit of the program: the point are not considered as snap, so you can correctly viewing it, without using it to exactly define the shape of the elements. On the other hand, Archicad works in quite different way. It is not able to import big cloud, so before starting that operation, it is necessary to reduce it. Once you have a smaller point cloud, you can import it and thank to the add-on Archisuite and in particular, with Architools, it is possible to recognize the point as 3D elements and using them to trace the shape, Figure 4. However, it is clear that with this method, you lose the level of detail because of the previous reduction of the cloud.

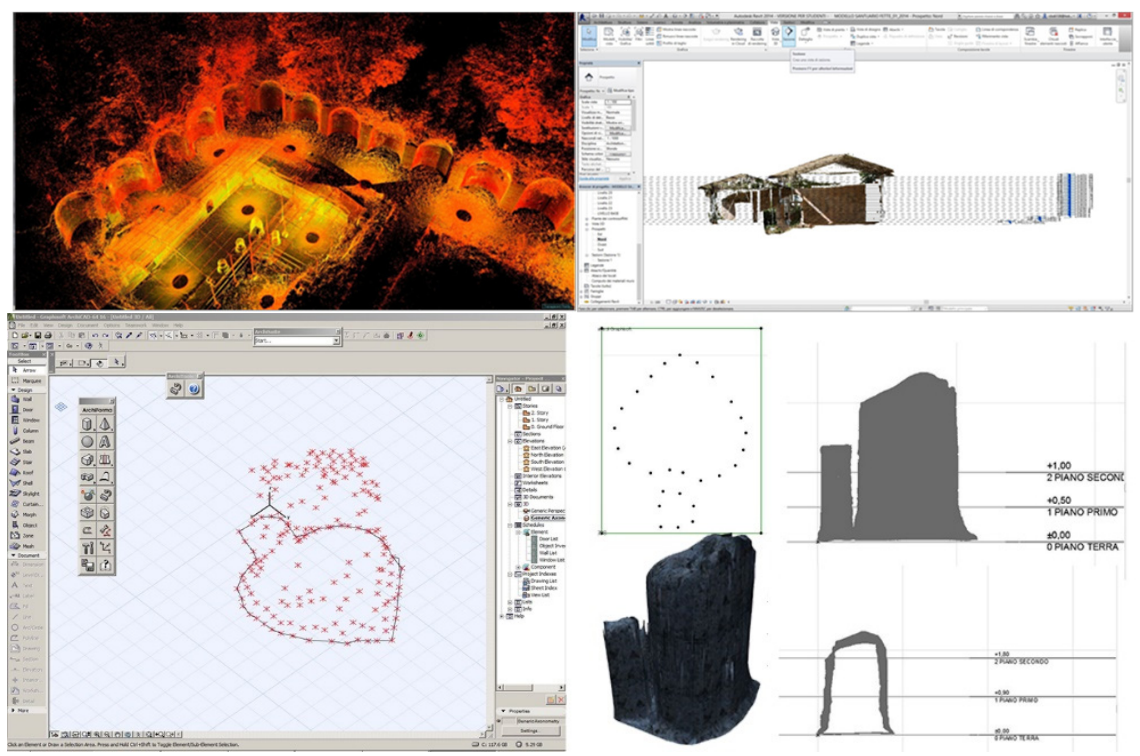

Figure 4: Top line: original point cloud and elaboration in Revit; Bottom line: approximate design of a section of a column from the Sanctuary, with $3 \mathrm{D}$ mesh visualization created by importing the survey data of the column. 


\subsection{Parametric modelling}

The 3D modelling of the archaeological area was made in different ways, which lead to different results and built the final model. The modelling of the coverage project (existing and new one) reached a very high level of detail, while the modelling of the ruins, created many difficulties, and the result is enough satisfactory.

Regarding the modelling part, when you work on these platforms, there is a simplification caused by the parameterization of the elements, that has to became more flexible and embrace the irregularities and the unicity of an historical building or an archaeological area.

The modelling phase is complicate and (at the moment) time consuming, but there are significant advantages in using it but if able to reach a sufficient Level of Detail (LOD), we obtain a model inside an information system.

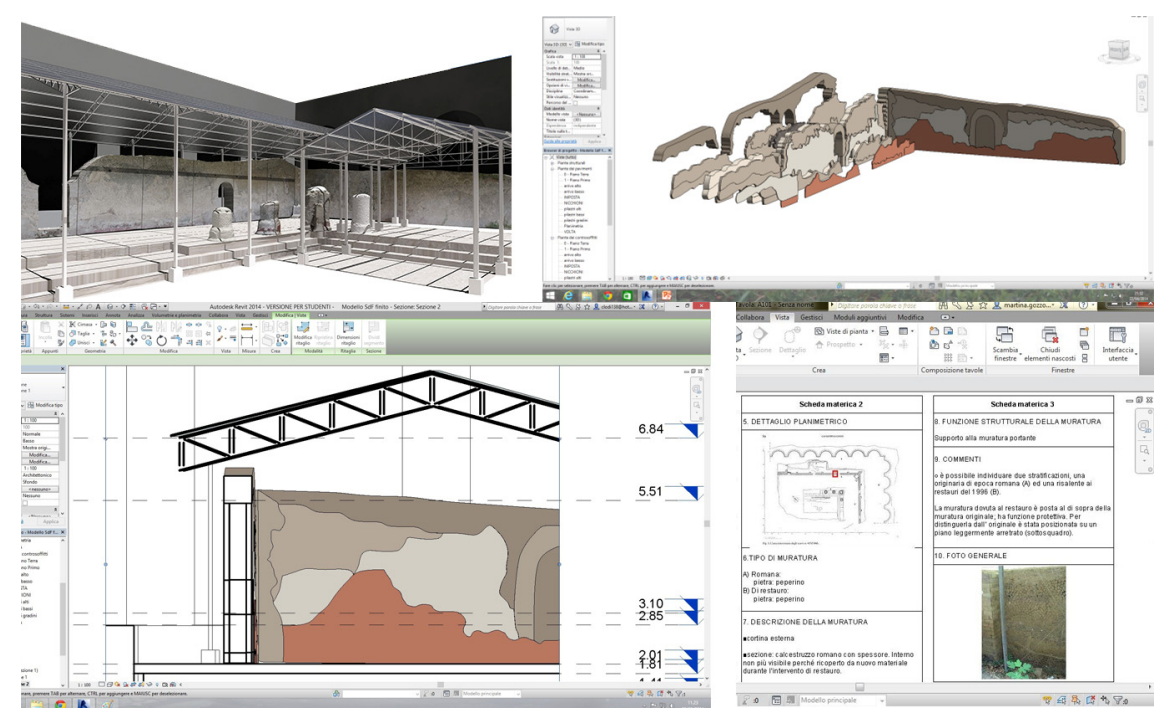

Figure 5: Top line: how the final render of the 3D model looks like (on the left) and how it is built - stratifications of the wall (on the right). Bottom line: visualization of the annotations of a part of the wall.

\section{Conclusions}

Ultimately, although there are several instruments that help the BIM software to return the historical buildings, the applications need to be perfect and shaped on the needs of who survey and model these type of elements. The models of the "portico", of the existing coverage and of the new coverage in the Sanctuary of Diana in Nemi improved/implemented by the two BIM softwares don't and cannot 

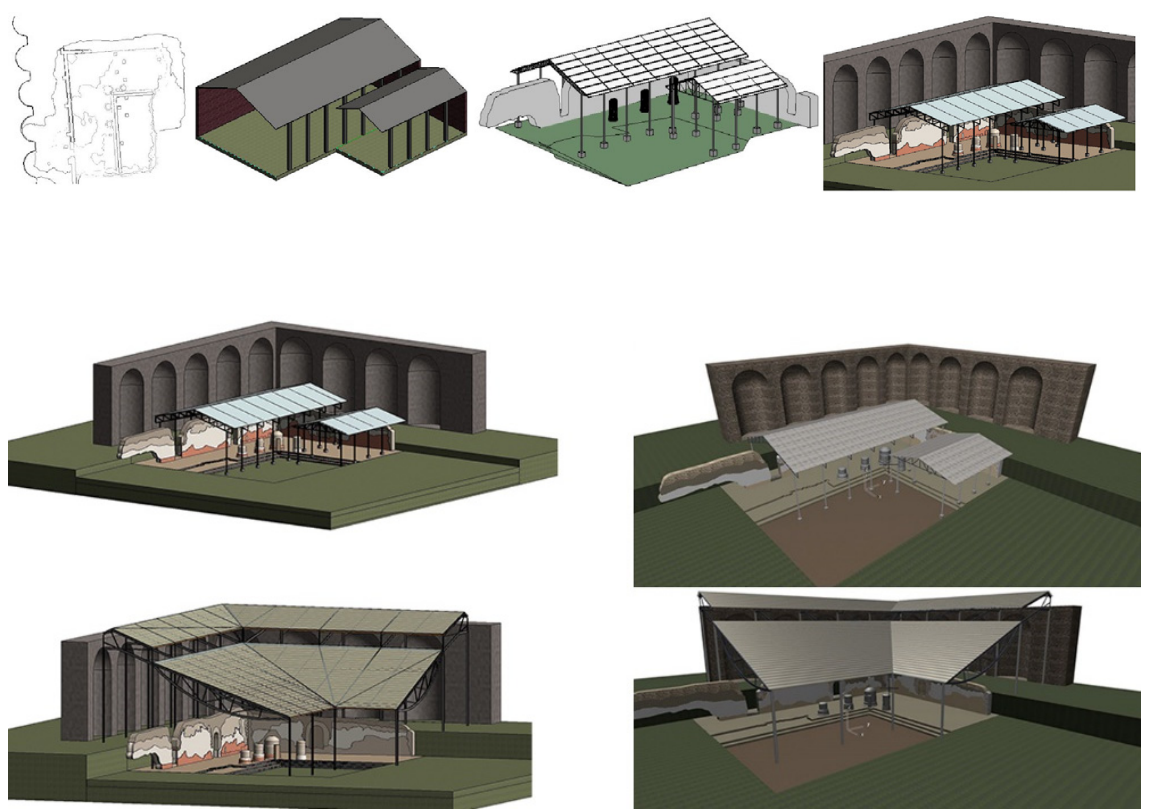

Figure 6: Top line: the different LOD created: from the 'conceptual level' (mass model) up to the level that contains all the graphic details and information. Bottom line: comparison between the two final model (Autodesk Revit on the left and Graphisoft Archicad on the right): existent and project state.

acquire all the information. After these tests on the two BIM software, the model does not contain all the information that it should have, but with the help of external modeller, it reaches a sufficient level of detail. Even if we succeed to model the area, and put some information inside it, there is not yet a complete level of interoperability, especially between the survey data and the BIM software not even between the parametric and non-parametric ones. Some steps in that direction are been done: for example from ArchiCAD 18 is possible to import/export directly from/to Rhinoceros, and the point cloud management is easier. In conclusion, we can say that a lot has to be done yet to use this type of software easily in the $\mathrm{CH}$ field, but we feel that the technologic barrier will be overcome very soon. For this reason, it is important to keep updated because the BIM process is in progress, and it is directed towards the $\mathrm{CH}$ world. 
Table 1: Recap of the characteristics of the BIM process applied to the archaeological area.

\begin{tabular}{|c|c|c|c|c|}
\hline $\begin{array}{l}\text { Model features and } \\
\text { data management }\end{array}$ & BIM software & $\begin{array}{l}\text { Level of } \\
\text { management: } \\
\text { good }\end{array}$ & $\begin{array}{l}\text { Level of } \\
\text { management: } \\
\text { sufficient }\end{array}$ & $\begin{array}{c}\text { Level of } \\
\text { management: } \\
\text { insufficient }\end{array}$ \\
\hline \multirow{2}{*}{$\begin{array}{l}\text { Text data: } \\
\text { a) Extended } \\
\text { b) Punctual }\end{array}$} & Revit 2014 & & a. & b. \\
\hline & Archicad 17 & b. & a. & \\
\hline \multirow{2}{*}{$\begin{array}{l}\text { Raster data: } \\
\text { a) Retracing support } \\
\text { b) Material survey } \\
\text { c) Decay survey } \\
\text { d) Photo database }\end{array}$} & Revit 2014 & b. & a. & c. d. \\
\hline & Archicad 17 & a. b. & & c. d. \\
\hline \multirow{2}{*}{$\begin{array}{l}\text { Vectorial data: } \\
\text { a) CAD files } \\
\text { b) Non parametric } \\
\text { c) Point clouds }\end{array}$} & Revit 2014 & & a. c. & b. \\
\hline & Archicad 17 & a. & b. & c. \\
\hline \multirow{2}{*}{$\begin{array}{l}\text { Modelling: } \\
\text { a) Importing external } \\
\text { elements from non- } \\
\text { parametric software } \\
\text { b) Use of IFC files } \\
\text { c) Modelling }\end{array}$} & Revit 2014 & & b. c. & a. c. \\
\hline & Archicad 17 & b. c. & c. & a. \\
\hline
\end{tabular}

\section{References}

[1] ICOMOS, Charter for the protection and management of the Archaeological Heritage, Prepared by the International Committee for the Management of Archaeological Heritage (ICAHM) and approved by the 9th General Assembly in Lausanne in 1990.

[2] D.L. of the $22^{\text {nd }}$ Jen. 2004, $\mathrm{n}^{\circ} 42$, Codice dei Beni Culturali e del Paesaggio, Gazzetta Ufficiale ${ }^{\circ}$ 45, 24 febbraio 2004.

[3] HARPACEAS, www.harpaceas.it

[4] A. Scianna, S. Gristina, S. Paliaga, Experimental BIM Applications in Archaeology: A Work-Flow. Proc. of the $5^{\text {th }}$ Int. Conf. on Digital Heritage. Progress in Cultural Heritage: Documentation, Preservation, and Protection, eds. M. Ioannides, N. Magnenat-Thalmann, E. Fink, R. Žarnić, A. Yianing Yen \& E. Quak: Limassol, pp. 490-498, 2014.

[5] AUTODESK REVIT, http://www.autodesk.it

[6] C. Dore , M. Murphy, Semi-automatic modelling of building façades with shape grammars using historic building information modelling, Proc. of the Int. Conf, on 3D ARCH 2013 - 3D Virtual Reconstruction and Visualization of Complex Architectures, eds. J. Boehm, F. Remondino, T. Kersten, T. Fuse \& D. Gonzalez-Aguilera: Trento, pp. 57-64, 2013. 
[7] S., Fai, K., Graham, T., Duckworth, N., Wood, R., Attar: Building Information Modeling and heritage documentation. Proc. of the $23^{\text {rd }}$ Int. CIPA Symposium, ed. K. Pavelka: Praga, pp. 43-48, 2011.

[8] C., Dore, M., Murphy: Integration of Historic BIM (HBIM) and 3D GIS for Recording and Managing Cultural Heritage Sites. Proc. of the 18th Int. Conf. on Virtual Systems and Multimedia (VSMM): Milano, pp. 369-376, 2012.

[9] S. Garagnani, A. M. Manferdini, Parametric accuracy: building information modeling process applied to the cultural heritage preservation, Proc. of the Int. Conf, on 3D ARCH $2013-3$ D Virtual Reconstruction and Visualization of Complex Architectures, eds. J. Boehm, F. Remondino, T. Kersten, T. Fuse \& D. Gonzalez-Aguilera: Trento, pp. 87-92, 2013.

[10] Scalypso, http://www.allplan.com/it/software/altresoluzioni/scalypso.html

[11] Nuove Norme Tecniche per le Costruzioni, DM 14 gennaio 2008, pubblicato sulla Gazzetta Ufficiale n. 29 del 4 febbraio 2008 - Suppl. Ordinario n. 30 Aggiornamento al 2014: 11/03/2015 Revisione delle Norme tecniche per le costruzioni 2008, Testo approvato dall'assemblea del CSLLPP, del 14 novembre 2014.

[12] Building Smart, www.buildingsmart.org 